\title{
Demand-side decarbonization and electrification: EMF 35 JMIP study
}

\author{
Shogo Sakamoto ${ }^{1}$ (D) Yu Nagai ${ }^{2} \cdot$ Masahiro Sugiyama $^{3} \cdot$ Shinichiro Fujimori $^{4,5} \cdot$ Etsushi Kato $^{6} \cdot$ Ryoichi Komiyama $^{7}$. \\ Yuhji Matsuo $^{8} \cdot$ Ken Oshiro ${ }^{4} \cdot$ Diego Silva Herran $^{5,9}$
}

Received: 26 June 2020 / Accepted: 26 February 2021 / Published online: 2 March 2021

(c) The Author(s) 2021

\begin{abstract}
Japan's long-term strategy submitted to the United Nations Framework Convention on Climate Change emphasizes the importance of improving the electrification rates to reducing GHG emissions. Using the five models participating in Energy Modeling Forum 35 Japan Model Intercomparison project (JMIP), we focused on the demand-side decarbonization and analyzed the final energy composition required to achieve $80 \%$ reductions in GHGs by 2050 in Japan. The model results show that the electricity share in final energy use (electrification rate) needs to reach $37-66 \%$ in 2050 (26\% in 2010 ) to achieve the emissions reduction of $80 \%$. The electrification rate increases mainly due to switching from fossil fuel end-use technologies (i.e. oil water heater, oil stove and combustion-engine vehicles) to electricity end-use technologies (i.e. heat pump water heater and electric vehicles). The electricity consumption in 2050 other than AIM/Hub ranged between 840 and $1260 \mathrm{TWh}$ (AIM/Hub: 1950TWh), which is comparable to the level seen in the last 10 years $(950-1035 \mathrm{TWh})$. The pace at which electrification rate must be increased is a challenge. The model results suggest to increase the electrification pace to $0.46-1.58 \% / y r$ from 2030 to 2050. Neither the past electrification pace (0.30\%/year from 1990 to 2010) nor the outlook of the Ministry of Economy, Trade and Industry (0.15\%/year from 2010 to 2030) is enough to reach the suggested electrification rates in 2050. Therefore, more concrete measures to accelerate dissemination of electricity end-use technologies across all sectors need to be established.
\end{abstract}

Keywords Demand-side decarbonization $\cdot$ Electrification $\cdot$ Multi-model scenario analysis

\section{Introduction}

\section{Background}

Handled by Kenichi Wada, Research Institute of Innovative Technology for the Earth, Japan.

Shogo Sakamoto

sakshogo@ criepi.denken.or.jp

1 Environmental Science Research Laboratory, Central Research Institute of Electric Power Industry, 1646 Abiko, Abiko-shi, Chiba 270-1194, Japan

2 Socio-Economic Research Center, Central Research Institute of Electric Power Industry, 1-6-1 Otemachi, Chiyoda-ku, Tokyo 100-8126, Japan

3 Institute for Future Initiatives, The University of Tokyo, 7-3-1 Hongo, Bunkyo-ku, Tokyo 113-0033, Japan

4 Graduate School of Engineering, Kyoto University, Kyoto daigaku-katsura, Nishikyo-ku, Kyoto 615-8530, Japan
Under the Paris Agreement, Japan pledged to reduce its greenhouse gas (GHG) emissions by $26 \%$ by 2030 from the

5 National Institute for Environmental Studies, 16-2 Onogawa, Tsukuba, Ibaraki 305-8506, Japan

6 Institute of Applied Energy, 1-14-2 Nishi-Shimbashi, Minato, Tokyo 105-0003, Japan

7 School of Engineering, The University of Tokyo, Hongo 7-3-1, Bunkyo-ku, Tokyo 113-8656, Japan

8 Institute of Energy Economics, Kachidoki 1-chome, Chuo-ku, Tokyo 104-0054, Japan

9 Institute for Global Environmental Strategies (IGES), 2108-11 Kamiyamaguchi, Hayama, Kanagawa 240-0115, Japan 
2013 levels and cut emissions by $80 \%$ by 2050 (Government of Japan 2019). As of 2018, the GHG emissions stood at $1240 \mathrm{Mt}-\mathrm{CO} 2 \mathrm{e}$, and around 50\% were direct emissions from the demand-side (Industry 25\%, Residential 5\%, Commercial 5\%, and Transportation 18\%) (Ministry of the Environment 2020).

The power sector is going through a major reform in Japan, and a rapid deployment of renewable energy has been contributing to supply-side decarbonization. In parallel with supply-side actions, it is also crucial to promote demandside decarbonization (Luderer et al. 2018; Duscha et al. 2019). Sugiyama et al. (2019) shows that the demand-side, especially the industry sector, has the difficulty of achieving emissions reductions in Japan's energy system.

Energy efficiency improvements are the first and useful contributions in reducing emissions (Fujimori et al. 2014; Sugiyama et al. 2014; Wakiyama and Kuramochi 2017), but switching the demand-side to clean energy carriers (electricity, hydrogen, and bioenergy) is equally important (Deep Decarbonization Pathways Project 2015; Ozawa et al. 2018; Matsuo et al. 2018; Gambhir et al. 2019; Wachsmuth and Duscha 2019). In fact, the Government of Japan has introduced electrification as one of the key policy areas along with increasing use of bioenergy and hydrogen (Government of Japan 2019).

Notably, among clean energy carriers, numerous studies show that a transition to electricity by the demand-side plays a pivotal role in large-scale $\mathrm{CO}_{2}$ reduction of all demand sectors on a global, national and urban scale (Sugiyama 2012; Williams et al. 2012; Wei et al. 2013, Intergovernmental Panel on Climate Change (IPCC) 2014; Quiggin and Buswell 2016; Raghavan et al. 2017; IPCC 2018; Fortes et al. 2019; Hill et al. 2019; Luh et al. 2020; Zhang and Fujimori 2020).

Electrification has been incorporated in Japan's long-term energy plans. The long-term low-carbon vision (Ministry of the Environment 2016), an input from the Ministry of the Environment to the policy debate on the long-term strategy, listed electrification, including a switch from combustionengine vehicles to electric vehicles and diffusion of heat pumps for space and water heating, as one of the three pillars to achieve low-carbon society in Japan. The 2019 long-term strategy submitted by Japan to the United Nations Framework Convention on Climate Change also emphasizes the need to increase electrification rates for 2050 .

In contrast to the policy directions, there are only a few concrete policies on electrification and most of them have been subsidies or RD\&D projects (Government of Japan 2019). One can contrast this with more drastic measures such as a ban on ICE cars in the United Kingdom (Government of UK 2017) and a proposal of a ban on the use of natural gas in the buildings (Deason and Borgeson 2019) in the west coast of the United States of America.

\section{Research questions and aims}

As mentioned above, while Japan's Nationally Determined Contribution (NDC) proposes an increasing share of electricity in 2030, Japan's mid-century strategy lacks a concrete level of electrification. The low-carbon vision from the Ministry of Environment and Japan's long-term strategy also do not reveal quantitative electrification pathways through 2050 . Therefore; this study examines 2050 low-carbon scenarios more concretely, with a focus on electrification pathways.

There are two dimensions that deserve detailed examination.

First, how high and fast should the share of electricity increase in the midst of competition from other clean energy carriers? Where and how much electrification contributes to mitigation needs to be assessed, as electricity is not the only clean energy carrier, and the role of electricity would be different by sectors. Oshiro et al. (2017) shows that for Japan to achieve an $80 \%$ emissions reduction in 2050 , it is necessary to accelerate the pace of electrification and reach the electrification rate of $45 \%$ in 2050 . However, the longterm energy demand and supply outlook by the Ministry of Economy, Trade and Industry (hereinafter called METI outlook), which is consistent with Japan's NDC, shows the share of electricity in final energy (electrification rate) in 2030 to be $29 \%$, a mere 3\% increase from 2013.

Second, would decarbonization increase the total demand for electricity? Increasing the electrification rate and decreasing the fossil fuel consumption is an effective way to reducing demand-side emissions. However, increasing the electrification rate does not automatically increase its absolute demand. Sugiyama (2012) reviewed global decarbonization pathways and found the electrification rate to increase with more stringent emissions targets, but the absolute demand of electricity did not always increase.

These two aspects are both dependent on a number of scenario assumptions as well as models. This study employs the multi-model analytic framework of Energy Modeling Forum (EMF) 35 Japan Model Intercomparison Project (JMIP) and characterizes future electrification pathways for Japan to achieve the long-term emissions reduction goals. In particular, the present paper takes advantage of a framework that includes various power supply technologies scenarios.

Oshiro et al. (2019) is a notable study in a multi-model framework which focused on a Japan's in-depth decarbonization scenario. Although the study shows the share of clean energy carriers grows in final energy use, electrification pace, supply-side technology uncertainty, nor the total demand for electricity are analyzed. The present study attempts to fill the gap by finding a common pattern among results of multiple models of different types to draw a 
Table 1 Final energy carriers reported by each model

\begin{tabular}{|c|c|c|c|c|c|c|c|c|c|}
\hline \multirow[t]{3}{*}{ Sector } & \multirow[t]{3}{*}{ Model } & \multicolumn{8}{|c|}{ Final energy carriers } \\
\hline & & \multirow[t]{2}{*}{ Electricity } & \multirow[t]{2}{*}{ Gases $^{b}$} & \multirow[t]{2}{*}{ Liquids $^{\mathrm{c}}$} & \multirow[t]{2}{*}{ Solids ${ }^{\mathrm{d}}$} & \multirow[t]{2}{*}{ Hydrogen } & \multicolumn{3}{|c|}{ Other all } \\
\hline & & & & & & & Heat & Solar & Other \\
\hline \multirow[t]{5}{*}{ Overall } & AIM/Enduse & $\mathrm{X}$ & $\mathrm{X}$ & $\mathrm{X}$ & $X$ & $\mathrm{X}$ & $\mathrm{X}$ & $\mathrm{X}$ & $\mathrm{X}$ \\
\hline & AIM/Hub & $\mathrm{X}$ & $X$ & $\mathrm{X}$ & $X$ & & $X$ & & \\
\hline & $\mathrm{DNE} 21^{\mathrm{a}}$ & $X$ & $X$ & $X$ & $X$ & & & & \\
\hline & IEEJ & $\mathrm{X}$ & $X$ & $X$ & $X$ & $\mathrm{X}$ & $X$ & & \\
\hline & TIMES-Japan & $\mathrm{X}$ & $X$ & $X$ & $X$ & $\mathrm{X}$ & $\mathrm{X}$ & $\mathrm{X}$ & $\mathrm{X}$ \\
\hline \multirow[t]{4}{*}{ Industry } & AIM/Enduse & $X$ & $X$ & $X$ & $X$ & & & & $X$ \\
\hline & AIM/Hub & $\mathrm{X}$ & $X$ & $X$ & $X$ & & & & \\
\hline & IEEJ & $\mathrm{X}$ & $X$ & $\mathrm{X}$ & $X$ & $\mathrm{X}$ & $X$ & & \\
\hline & TIMES-Japan & $X$ & $X$ & $X$ & $X$ & $\mathrm{X}$ & $X$ & $X$ & $X$ \\
\hline \multirow[t]{4}{*}{ Residenital } & AIM/Enduse & $\mathrm{X}$ & $X$ & $X$ & $X$ & $\mathrm{X}$ & & $\mathrm{X}$ & $\mathrm{X}$ \\
\hline & AIM/Hub & $X$ & $X$ & $X$ & $X$ & & $X$ & & \\
\hline & IEEJ & $\mathrm{X}$ & $X$ & $\mathrm{X}$ & & & $X$ & $\mathrm{X}$ & \\
\hline & TIMES-Japan & $X$ & $X$ & $X$ & $X$ & $X$ & $X$ & $X$ & $X$ \\
\hline \multirow[t]{4}{*}{ Commercial } & AIM/Enduse & $X$ & $X$ & $X$ & $X$ & $X$ & $X$ & $X$ & $X$ \\
\hline & AIM/Hub & $\mathrm{X}$ & $X$ & $X$ & $X$ & & $X$ & & \\
\hline & IEEJ & $X$ & $X$ & $X$ & $X$ & & $X$ & & \\
\hline & TIMES-Japan & $\mathrm{X}$ & $X$ & $X$ & $X$ & $\mathrm{X}$ & $X$ & $X$ & $X$ \\
\hline \multirow[t]{4}{*}{ Transportation } & AIM/Enduse & $\mathrm{X}$ & & $\mathrm{X}$ & & $X$ & & & \\
\hline & AIM/Hub & $X$ & $X$ & $X$ & & & & & $X$ \\
\hline & IEEJ & $X$ & $X$ & $X$ & & $\mathrm{X}$ & & & \\
\hline & TIMES-Japan & $\mathrm{X}$ & $X$ & $X$ & & $\mathrm{X}$ & & & $X$ \\
\hline
\end{tabular}

Variables that are not reported can be represented in the model. When calculating the emissions, the difference in emissions factors of petroleum, gas, biofuel, etc. is properly taken into consideration

${ }^{a}$ In DNE21, demand sector is not modeled separately

${ }^{b}$ Gases include natural gas, biogas, coal-gas, excluding transmission/distribution losses

${ }^{c}$ Liquids include conventional \& unconventional oil, biofuels, coal-to-liquids, gas-to-liquids

${ }^{\mathrm{d}}$ Solids include coal and solid biomass general conclusion related to the role of electricity in decarbonizing the demand sector of Japan.

\section{Methods}

\section{Model description}

This study employs scenarios from five energy-economic and integrated assessment models: AIM/Enduse-Japan (Oshiro and Masui 2015; Fujimori et al. 2019; Kainuma et al. 2003), AIM/Hub-Japan (Fujimori et al. 2017a, b, c; Silva et al. 2019), DNE21 (Hosoya and Fujii 2011; Fujii and Komiyama 2015), IEEJ_Japan 2017 (Matsuo et al. 2013, 2020), and TIMES-Japan (Kato and Kurosawa 2019; Kurosawa and Hagiwara 2012; Loulou et al. 2005; Sato 2005). Hereafter, each model is called AIM/Enduse, AIM/Hub, DNE21, IEEJ, and TIMES-Japan. AIM/Enduse and AIM/ Hub are recursive dynamic models. The former is a typical energy system model that minimizes total energy system cost considering numerous detailed technological representation in both energy supply and demand sectors, and the latter is a general equilibrium model with relatively aggregated technological resolution but can consider the macroeconomic responses considering the sectoral input-output changes in detail. DNE21, IEEJ and TIMES-Japan are perfect foresight models. Only AIM/Hub is a general equilibrium model, and others are partial equilibrium models.

Since energy demand representation is much more heterogeneous across models than supply-side structures, it is favorable to have an overview of the decomposition of sectors and the inclusion of different final energy carriers. The reason for different model behaviors could be attributable to which final energy carrier is explicitly represented.

Table 1 clarifies final energy carriers by sectors reported by the participating models. Electricity is included in all models while hydrogen is represented in AIM/Enduse, IEEJ, and TIMES-Japan. Some models do not report biomassrelated carrier (solids biomass, biofuels, and biogas) separately. These carriers are reported in an aggregated manner 
and included in the corresponded carriers (solids, liquids, and gases). Note that DNE21 does not explicitly represent energy services by sectors; instead, their demands are represented as fuel demands. Also, AIM/Hub does not represent energy services, yet fuel demands are represented for each sector. Detailed end-use technologies by models are shown in ESM (Table ESM1 to 4). The more detailed model descriptions are provided in Sugiyama et al. (2021).

\section{Scenarios}

We briefly describe the salient aspects of the scenarios that are analyzed in this paper (see Sugiyama et al. 2021 for fuller descriptions).

The central scenario is a mitigation scenario that is consistent with the NDC and mid-century strategy ${ }^{1}$ (26by30+80by50_Def). The "Baseline" scenario is a scenario with no climate policy.

We also consider an extensive list of sensitivity runs on variable renewables (VREs) and nuclear generation. It is now well established that the power sector needs to go through almost a complete decarbonization in the long run (IPCC 2014, 2018). Cheap clean electricity makes electrification economically competitive, and can further promote demand-side electrification (Zhang et al. 2012). However, the availability of affordable clean electricity depends on multiple technological parameters. It is therefore useful to examine the impact of supply-side sensitivities on demandside electrification.

The JMIP study also explores a scenario regarding the availability of Carbon Capture and Storage (CCS) in addition to VREs and nuclear power generation technology. Since CCS can be deployed both in the power generation sector and the industry sector, it can be a crucial technology to decrease demand-side emissions.

This paper considers the following scenarios:

- 26by30+80by50_LoVREcost: halving the costs of VREs;

- 26by30+80by50_HiVREcost: doubling the costs of VREs;

- 26by30 + 80by50_LoVREpot: Resource potential for wind and solar halved for 2020 and onwards;

- 26by30+80by50_HiVREpot: Resource potential for wind and solar doubled for 2020 and onwards; and

- 26by30+80by50_NoNuc: nuclear power is completely unavailable.

\footnotetext{
${ }^{1}$ Since the mid-century strategy does not specify the base year, the base year used to calculate $80 \%$ reduction differs among models (2010 in AIM/Enduse, 2005 in AIM/Hub, 2000 in DNE 21, 2013 in IEEJ, and 2013 in TIMES-Japan).
}

- 26by30+80by50_NoCCS: CCS is completely unavailable.

In the 26by30+80by50_LoVREcost, VRE's capital cost was halved compared to 26by30+80by50_Def, but the models did not harmonize the timing of the cost change. Hereafter, the scenario prefix " 26 by $30+80$ by 50 " is dropped for sensitivity scenarios in this paper for brevity in reporting.

We also examine different levels of emissions constraints. More stringent emissions constraint should accelerate demand-side decarbonization, resulting in higher clean energy carrier shares or electrification rates (Fortes et al. 2019). Targeting 2050, we consider $70 \%, 80 \%$, 90\%, and $100 \%$ emission reduction levels to understand the impacts of climate policies. In addition to 26 by $30+80$ by50_Def, we explore following scenarios:

$$
\begin{aligned}
& \text { 26by30+70by50_Def; } \\
& 26 \text { by } 30+90 \text { by } 50 \_D e f ; \text { and } \\
& 26 \text { by } 30+100 \text { by50_Def. }
\end{aligned}
$$

In the JMIP study, not all participating models have $90 \%$ and $100 \% \mathrm{CO}_{2}$ emissions reduction scenarios in 2050. In AIM/Enduse, 26by30 + 100by50_Def is infeasible, and in IEEJ and TIMES-Japan, 26by30+90by50_Def and 26 by $30+100$ by $50 \_$Def are infeasible. Therefore; pathways to achieve net carbon neutrality, a new pledge presented by Prime Minister Suga in October 2020 (Prime Minister's Office of Japan 2020), could not be elaborated in this paper. This is a future research issue.

\section{Results}

\section{Overall $\mathrm{CO}_{2}$ emissions and final energy use in 2050}

The $\mathrm{CO}_{2}$ emissions in 2050 for the 26 by $30+80$ by50_Def scenario are around $280 \mathrm{Mt}-\mathrm{CO}_{2}\left(237-336 \mathrm{Mt}-\mathrm{CO}_{2}\right)$. The supply side sees a sharp reduction to which the emissions are less than $100 \mathrm{Mt}-\mathrm{CO}_{2}$ in all models. However, the demand sector still emits approximately $200 \mathrm{Mt}-\mathrm{CO}_{2}(199-252 \mathrm{Mt}-$ $\mathrm{CO}_{2}$ ) (see Figure ESM 1.) showing that the demand-side reduction is crucial in achieving emissions reduction targets. The total amount of $\mathrm{CO}_{2}$ captured and stored is around $160 \mathrm{Mt}-\mathrm{CO}_{2}\left(23-350 \mathrm{Mt}-\mathrm{CO}_{2}\right)$, of which around $40 \mathrm{Mt}-\mathrm{CO}_{2}$ $\left(0-109 \mathrm{Mt}-\mathrm{CO}_{2}\right)$ is captured in the demand sector (the industry sector, including industrial processes). 
Fig. 1 Final energy use in 2010 and 2050 by fuels in 26by30+80by50_Def: a Final energy use in 2010 and 2050, b Difference in final energy use 2010 and 2050, c Fuel share in final energy use in 2010 and 2050, and d Difference of fuel share in final energy use 2010 and 2050

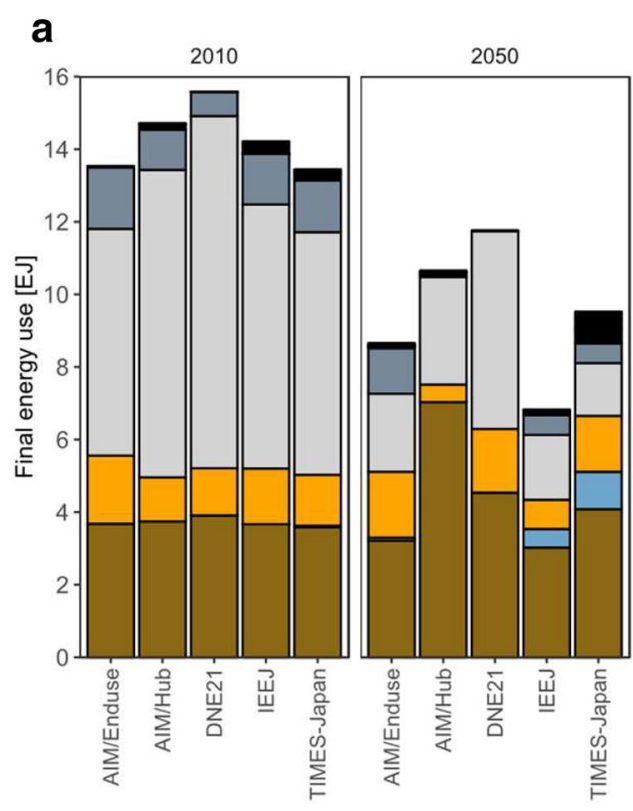

C
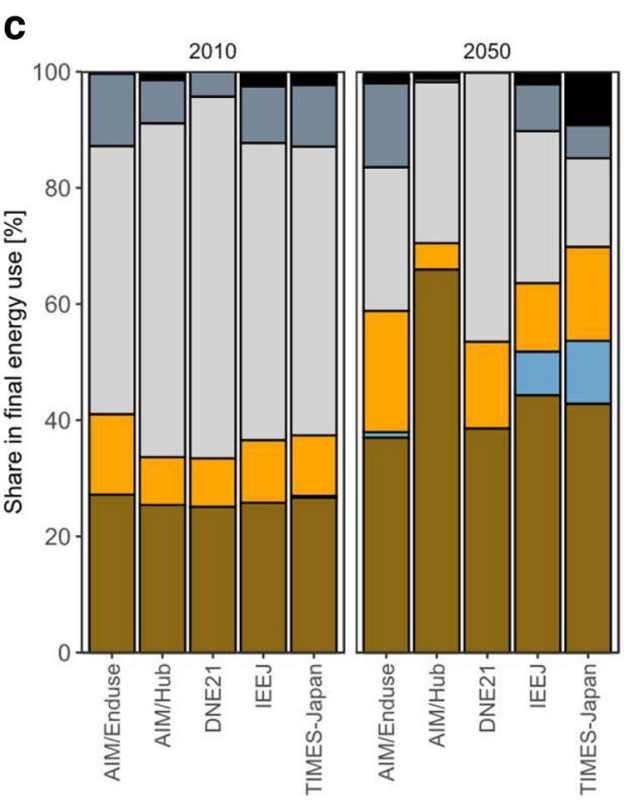

b

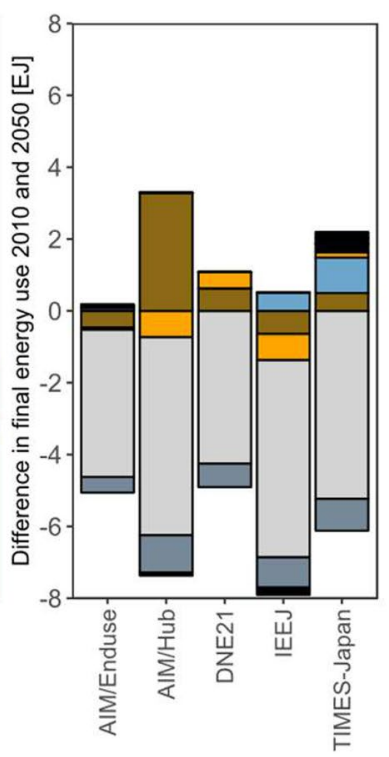

d

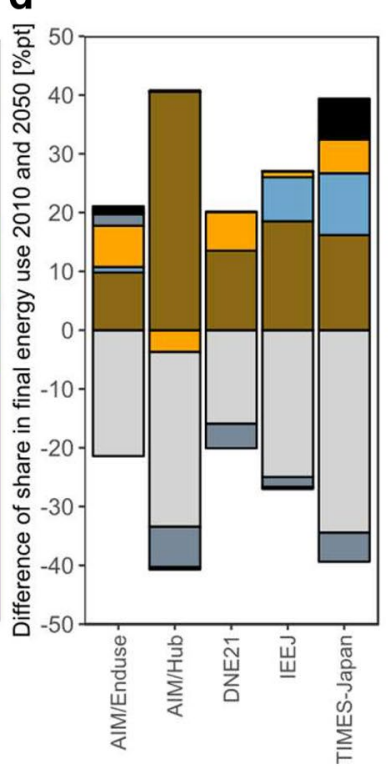

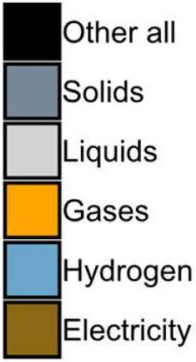

Electricity
Next, we present final energy (reported in lower heating value) by fuel types in $2010^{2}$ and 2050 for the 26 by $30+80$ by50_Def scenario (Fig. 1). One common trend among the models is a drastic decrease in liquids, mostly oil products, by 4.1EJ to 5.5EJ compared to 2010 (the reduction rate ranges from 44 to $78 \%$ ). A similar trend of decreasing consumption is observed in solids, which sees a decrease by about $1 \mathrm{EJ}$ in all models. Other energy carriers, electricity,

\footnotetext{
2 There is a discrepancy in the final energy use in 2010, the base year, as the participating models use different databases and have different industry sector representation (see Sugiyama et al. 2021).
}

hydrogen and gases, see different patterns depending on models.

All models show a substantial decrease in the final energy use from 2010 to 2050. The net final energy use decreases by $5 \mathrm{EJ}$ in AIM/Enduse and by $7 \mathrm{EJ}$ in IEEJ. Despite similar reduction in liquids and solids, the net final energy use only decreases around 4EJ in AIM/Hub, DNE21, and TIMES-Japan due to the increasing use of electricity, gas and hydrogen.

In AIM/Enduse, most fuels are reduced with only a slight increase in hydrogen and "other all (heat, solar, and other sources)". In IEEJ, only a slight increase in hydrogen is seen and significant energy savings in all other fuels. In AIM/Hub, DNE21, and TIMES-Japan electricity, gas and 
Fig. $2 \mathrm{CO}_{2}$ emissions and $\mathrm{CO}_{2}$ reduction rate by demand-side sectors in 26 by $30+80$ by 50

Def: a $\mathrm{CO}_{2}$ emissions in 2010 and 2050 , and $\mathbf{b} \mathrm{CO}_{2}$ reduction rate in 2050 from 2010. Note: DNE21 does not report $\mathrm{CO}_{2}$ emissions by sectors

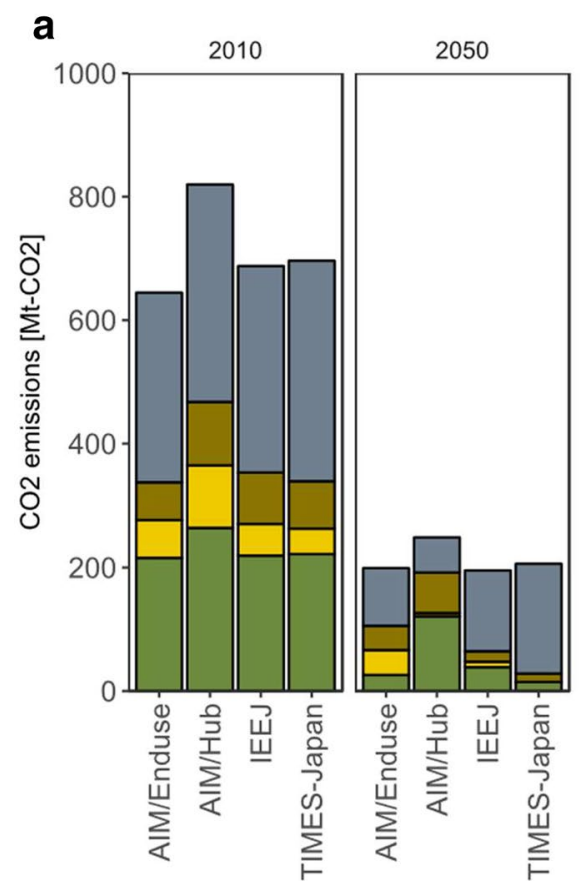

b

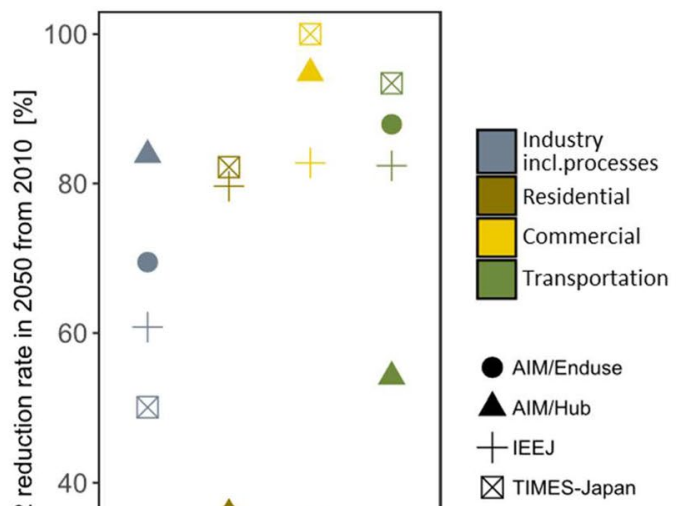

\section{$\mathrm{CO}_{2}$ emissions and final energy use by sectors in $\mathbf{2 0 5 0}$}

The overall direct $\mathrm{CO}_{2}$ emissions reduction rate of the demand-side from 2010 to 2050 is approximately $70 \%$, but the reduction rates by sectors vary across models as shown in Fig. 2. The $\mathrm{CO}_{2}$ emissions reduction rates are $50-84 \%$ in the industry sector including industrial processes, 36-82\% in the residential sector, $34-100 \%$ in the commercial sector, and $54-93 \%$ in the transportation sector.

The $\mathrm{CO}_{2}$ emissions in the transportation sector are the smallest in AIM/Enduse while they are the largest in AIM/ Hub. Both in IEEJ and TIMES-Japan, the largest emitting sector is the industry sector and the smallest is the commercial sector. However, in IEEJ, the $\mathrm{CO}_{2}$ emissions of the residential sector is about half of the transportation sector, but in TIMES-Japan, the residential sector and the transportation sector have almost the same $\mathrm{CO}_{2}$ emissions.

The variation among models is caused by the differences in final energy use changes in each sector from 2010 to 2050. Figure 3. shows the differences among models in the final energy use by fuels in industry, residential, commercial, and transportation sectors in 2010 and 2050. The industry sector continues to be the most consuming sector in all models despite the largest decrease in the final energy use among all sectors in most models. The transport sector goes through a rapid transition with a rapid decline in use of liquids (mostly oil products).

The final energy use in the industry sector in 2050 ranges between 3.3 and 5.7EJ, and the electricity consumption ranges between 0.8 and 2.5EJ. The share of final energy 
a Industry sector

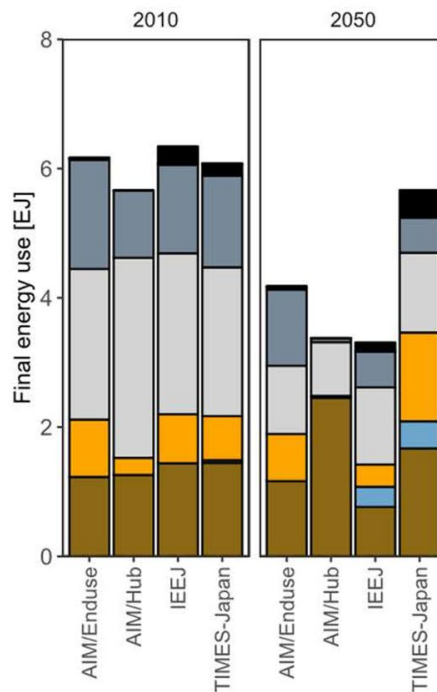

e Commercial sector

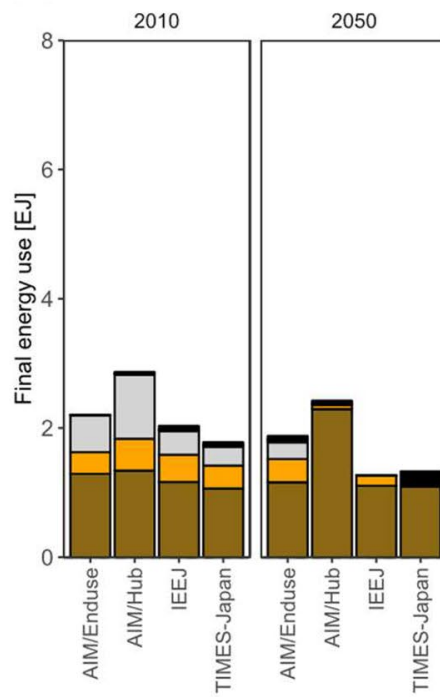

f
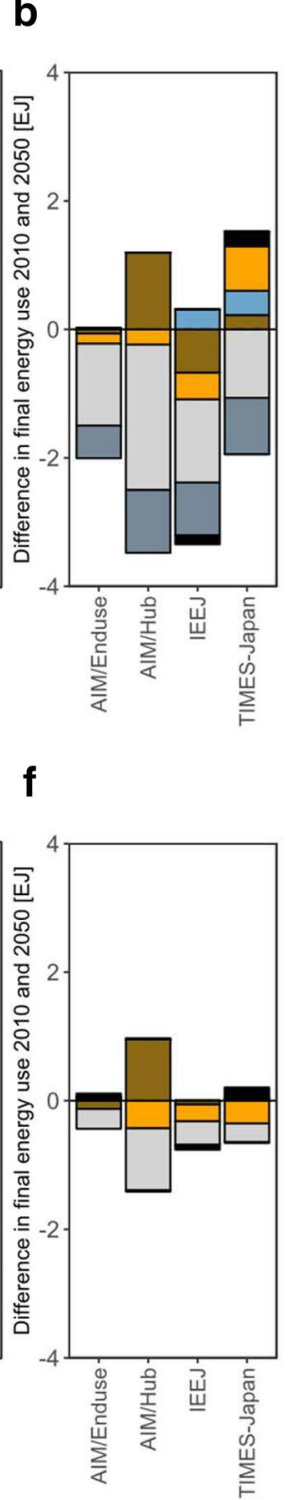

C

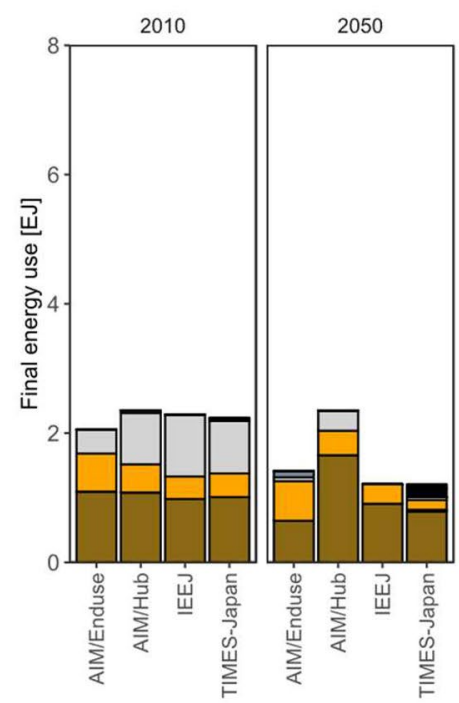

g Transportation sector

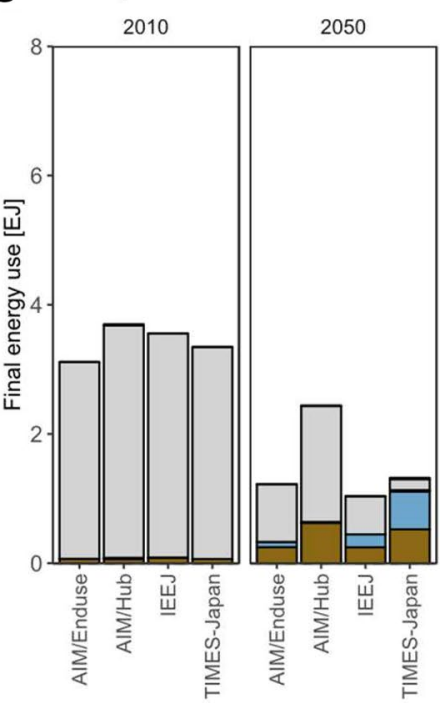

d

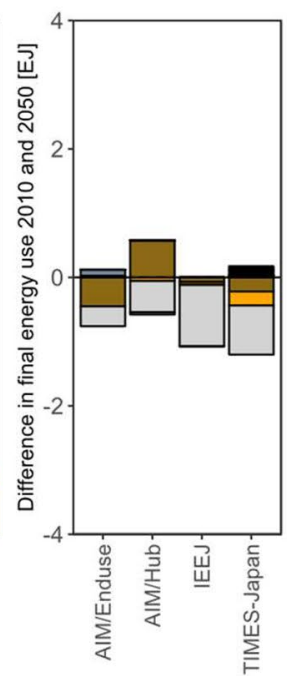

h

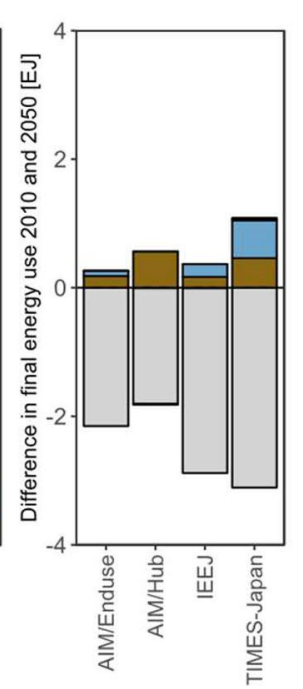

Fig. 3 Final energy use by fuel type by sector in 2010 and 2050 in 26by30+80by50_Def: a Final energy use in industry sector in 2010 and 2050, b Difference in final energy use 2010 and 2050 in industry sector, c Final energy use in residential sector in 2010 and 2050, d Difference in final energy use 2010 and 2050 in residential sector,

use by the industry sector in 2050 is $32-60 \%$, close to half in three models. The industry sector transforms its energy composition largely dependent on liquids and solids (around $60 \%$ in all models) in 2010 to delivering half of its energy from electricity, gases and hydrogen in 2050. Although the largest reduction is seen in liquids, the consumption of liquids still stays high around 1.2EJ in all models. Solids are also reduced in all models, but most models still use around $0.6 \mathrm{EJ}$ in 2050 .

The final energy use in the residential sector ranges between 1.2 and 2.4EJ of which gases and electricity make e Final energy use in commercial sector in 2010 and 2050, f Difference in final energy use 2010 and 2050 in commercial sector, g Final energy use in transportation sector in 2010 and 2050, and $\mathbf{h}$ Difference in final energy use 2010 and 2050 in transportation sector

up most of the demand. The reduction in liquids demand is a major movement in the residential sector as the liquids demand decreases to less than $0.1 \mathrm{EJ}$ in three models, implying that oil water heater and stoves are virtually phased out in the residential sector (Oshiro and Fujimori 2020). Most models see a decrease in the final energy demand, but AIM/ Hub sees an increase as the increase in electricity demand surpasses the decrease in liquids demand.

The final energy use in the commercial sector in 2050 is $1.3-2.4 \mathrm{EJ}$, of which electricity is the major energy carrier. The use of liquids and gases are greatly reduced and 


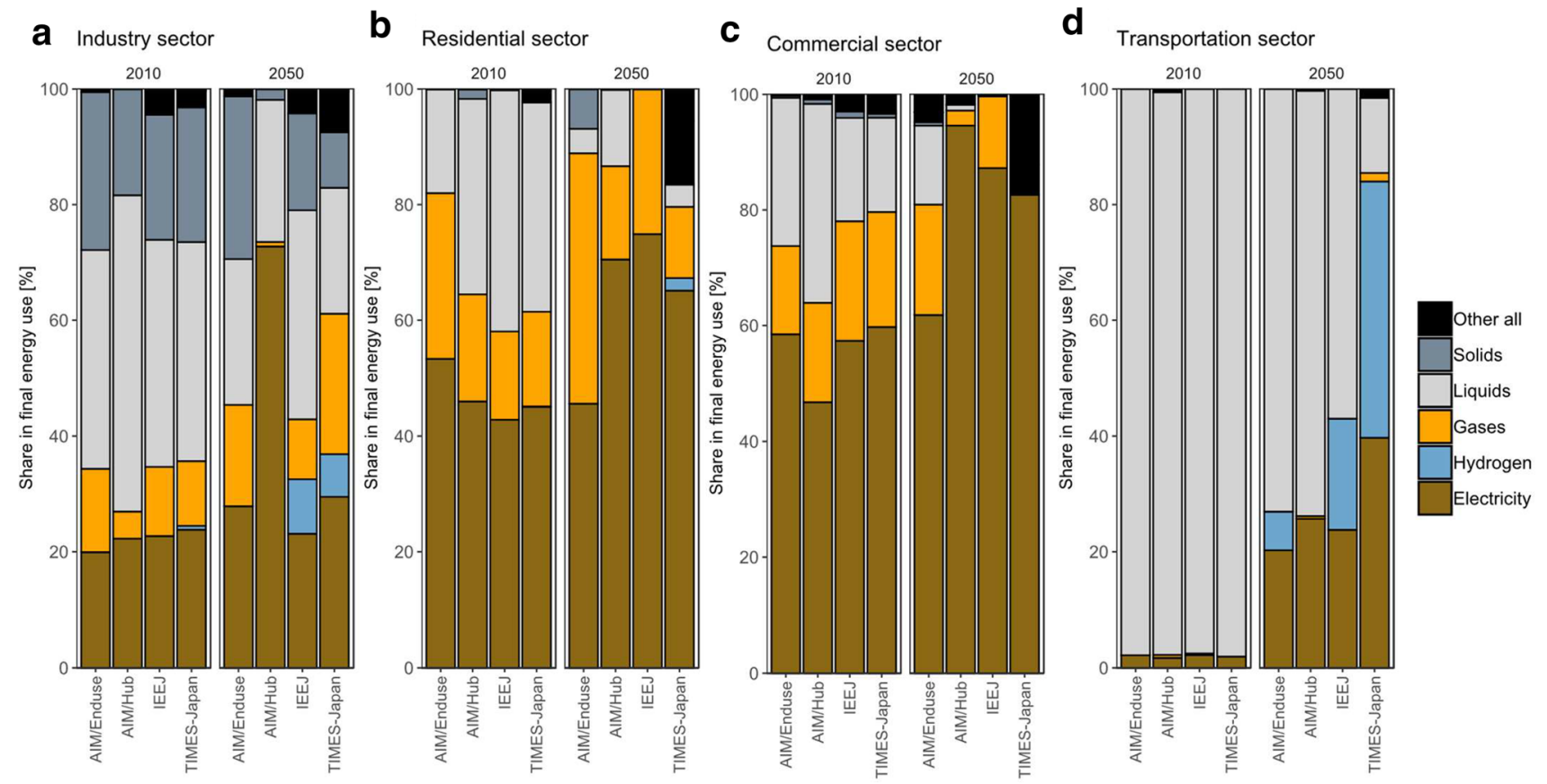

Fig. 4 Share of fuels in final energy by sectors in 2010 and 2050 in 26by30+80by50_Def: a Industry sector, b Residential sector, c Commercial sector, and $\mathbf{d}$ Transportation sector

almost no longer consumed ( $0-0.02 \mathrm{EJ}$ for liquids, $0-0.2 \mathrm{EJ}$ for gases) except for AIM/Enduse which has a relatively large $\mathrm{CO}_{2}$ emissions in the commercial sector. This implies that nearly all oil and gas appliances (mainly cooking, water heater, and space heating) needs to be phased out in this sector to reach emissions reduction targets.

The transportation sector sees a rapid transformation from heavily liquids dependent energy composition to a more mixed composition. Other than AIM/Hub, which does not model hydrogen, models see an increase in both electricity and hydrogen. The electricity consumption increases to $0.3-0.6 \mathrm{EJ}$, whereas the hydrogen consumption increases to $0.1-0.6 \mathrm{EJ}$. Since most of the energy use in the transportation sector was oil products in 2010, liquids consumption decreases by 1.3-2.5EJ. The replacing technologies (electric vehicles and hydrogen vehicles) typically have higher efficiency, so the final energy use in the sector reduces to 1.0-2.4EJ. The share of transportation sector in overall final energy, which was around $25 \%$ in 2010 , decreases to around $15 \%$ in most models.

Figure 4 shows fuel share of final energy use by sectors in 2010 and 2050. Two trends observed in all sectors from 2010 to 2050 are the decrease in the share of liquids and the increase in electrification rates (with the exception of the residential sector's electricity share in the AIM/Enduse). The electrification rates increase mainly due to decreasing consumption of other fuels in the industry and residential sectors. In the commercial and transport sectors, the increasing electrification rates is attributed also to the increasing consumption of electricity along with decreasing consumption of other fuels (see also Fig. 3).

In the industry sector, the electrification rate stays the lowest among sectors at around $20 \%$, an increase of only a few percentage points from 2010. One exception is the AIM/ Hub (the only participating GE model), in which rapid electrification takes place up to $73 \%$ in 2050.In the residential sector, the electrification rate is the highest among all fuels in all models (46-75\%), showing the importance in electrifying the residential end-use technologies. On the other hand, the share of liquids (mostly oil products) decrease significantly suggesting a need to initiating a phase out of oil water heater and stoves. The commercial sector, which has the highest electrification rate across sectors in all models (62-95\%), sees the use of liquids disappear in three models implying limited use of oil and gas appliances (mainly for cooking, hot water, and space heating) in a decarbonized society. The transport sector sees a great increase in the share of electricity. In 2010 the share is very low at around $2 \%$, but it increases to $20-40 \%$ in models.

As a complement, the share of hydrogen, a clean energy carrier competing with electricity, is described by sector. In the industry sector, hydrogen is introduced in 2050 with a share of $9 \%$ and $7 \%$ in IEEJ and TIMESJapan respectively, while the electrification rates reach $23 \%$ and $29 \%$. Likewise, in the transport sector, both electricity and hydrogen are introduced in 2050. In AIM/ 


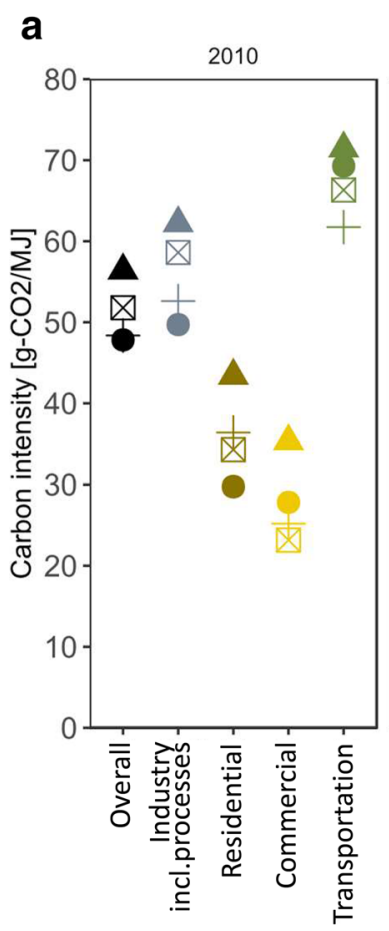

Fig. 5 Carbon intensity in 2010 and 2050 and relationship to electrification rate by sector in 2050 in 26 by $30+80$ by 50 _Def: a Carbon intensity by sector in 2010 and 2050, and $\mathbf{b}$ The relationship between

Enduse, electricity is $20 \%$ while hydrogen is $7 \%$ and in IEEJ, electricity is $24 \%$, hydrogen is $19 \%$. In TIMESJapan, the share of hydrogen is higher than electricity, with electricity at $40 \%$ while hydrogen at $44 \%$.

Carbon intensity (the emission amount per unit final energy use) is reduced across all models in 2050. Looking at the $\mathrm{CO}_{2}$ emissions (Fig. 2) and the final energy use (Fig. 3) in each sector from 2010 to 2050, the demand sector's carbon intensities in 2010 is $48-56 \mathrm{~g}-\mathrm{CO}_{2} / \mathrm{MJ}$, but they are reduced to $22-29 \mathrm{~g}-\mathrm{CO}_{2} / \mathrm{MJ}$ in 2050 (Fig. 5). The lowest carbon intensity is seen in the commercial sector $\left(0-22 \mathrm{~g}-\mathrm{CO}_{2} / \mathrm{MJ}\right)$, followed by the residential sector (11-28 g-CO $/ 2 / \mathrm{MJ})$. The model average of carbon intensity in the industry sector including industrial processes $\left(28{\mathrm{~g}-\mathrm{CO}_{2}}_{2} \mathrm{MJ}\right)$ and the transportation sector $\left(30 \mathrm{~g}-\mathrm{CO}_{2} /\right.$ MJ) remain to be high-emitting sectors.

The carbon intensity strongly depends on the ratio of fuel types in the final energy use. The value of carbon intensity increases as the share of fossil fuels increases, and the carbon intensity decreases as the share of clean energy carriers, such as electricity and hydrogen, increase. Therefore, sectors with high electrification rates have low-carbon intensities as shown in Fig. 5 and contribute greatly in reducing the demand-side emissions. electrification rate and carbon intensity by sector in 2050. Note: Carbon intensity calculates by only direct emissions without CCS in industry sector

\section{Sensitivity analysis}

\section{VREs and nuclear generation sensitivity}

In order to analyze the effects of available VREs and nuclear generation, scenarios with high and low VRE costs, high and low VRE resource potential, and no nuclear (LoVREcost, HiVREcost, HiVREpot, LoVREpot, and NoNuc) are compared. Figure 6 shows the share of energy carriers in each scenario by models. Although electrification rates are different in each model, all models maintain electrification rates close to the level of 26 by $30+80$ by50_Def scenario as the change ranges between -4.3 and $+6.5 \%$ pt (see also Figure ESM3).

A notable change in the share of final energy is seen in the following scenarios. AIM/Enduse shows a higher electrification rate $(+1.2 \% \mathrm{pt})$ in the HiVREcost scenario than the 26 by $30+80$ by50_Def scenario because the electricity consumption is slightly higher $(+0.01 \mathrm{EJ})$ while the final energy use decreases by $0.24 \mathrm{EJ}$. In AIM/Hub, the electrification rate decreases from the 26by30+80by50_Def scenario in the HiVREcost $(-4.3 \%$ pt $)$ and the NoNuc $(-2.2 \%$ pt $)$ scenarios by increasing liquids consumption, while the electrification rate increases from the 26 by $30+80$ by 50 Def scenario in the 


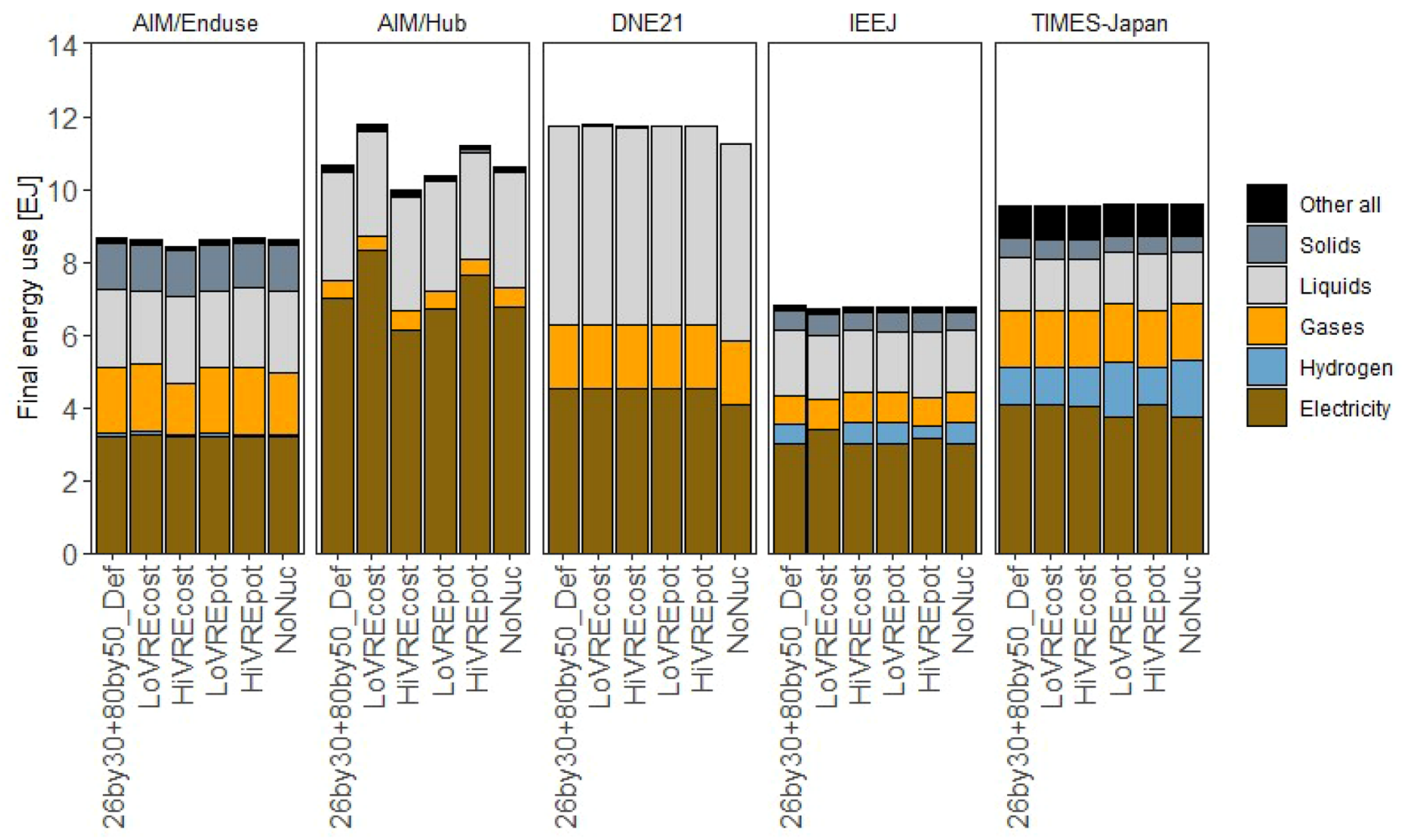

Fig. 6 Final energy mix in 2050 in VREs and nuclear generation sensitivity scenarios

LoVREcost (+4.5\%pt) and the HiVREpot (2.1\%pt) scenarios by decreasing liquids consumption. In DNE21, only the NoNuc scenario shows a slight decrease in the electrification rate $(-0.2 \%$ pt $)$ from 26 by $30+80$ by50_Def because DNE21 has a high share of nuclear power generation due to no quantity constraint (see Shiraki et al. 2021) in 26by30+80by 50 Def. IEEJ and TIMES-Japan models show a competitive nature between VRE and hydrogen. Hydrogen consumption decreases when more VREs electricity becomes accessible (LoVREcost and HiVREpot), while hydrogen consumption increases when electricity from VREs and nuclear becomes limited (HiVREcost, LoVREpot and NoNuc).

The electrification rate correlates positively with the availability of VREs and nuclear power sources, but the cases considered in this modeling exercise were not enough to change the electrification rates drastically. When availability of nuclear is restricted, VRE replaced the generation and vice versa. In summary, the cost and availability of VREs and nuclear generation does not change the need for electrifying the demand sector to achieve the $80 \%$ reduction in 2050 .

\section{CCS sensitivity}

Figure 7 shows the share of final energy carriers and $\mathrm{CO}_{2}$ emissions in the NoCCS scenario by models.
Models maintain electrification rates close to the level of 26 by $30+80$ by $50 \_D e f$ scenario as the change ranges only between -0.2 and $+1.8 \%$ pt. One exception is AIM/Enduse, which sees a notable increase of $8.8 \%$ pt as over $100 \mathrm{Mt}$ of $\mathrm{CCS}$ is deployed on the demand side (around $110 \mathrm{Mt}-\mathrm{CO}_{2}$ in the industry sector including industrial processes) in 26 by $30+80$ by50_Def. When CCS is not available, AIM/ Enduse decreases gas consumption and increases electricity demand to reduce $\mathrm{CO}_{2}$ emissions in the residential and commercial sectors to compensate for the increasing emissions in the industry sector.

\section{Emissions policy sensitivity}

Figure 8 shows the changes in the share of final energy carriers when the emission reduction target for 2050 is $70 \%, 80 \%$, $90 \%$, and $100 \%$ (26by $30+70$ by $50 \_$Def, 26by $30+80$ by 50 Def, 26by30 + 90by50_Def, and 26by30+100by50_Def). Some models were not able to provide results as the emissions policy became extremely stringent. (26by30+90by50_ Def: IEEJ, TIMES-Japan; 26by30 + 100by50_Def: AIM/ Enduse, IEEJ and TIMES-Japan).

When a stricter emissions reduction policy is applied, the electrification rates increase in all models (Fig. 9), showing the importance of electricity as a clean energy carrier in the demand sector. Electricity typically replaces gases 

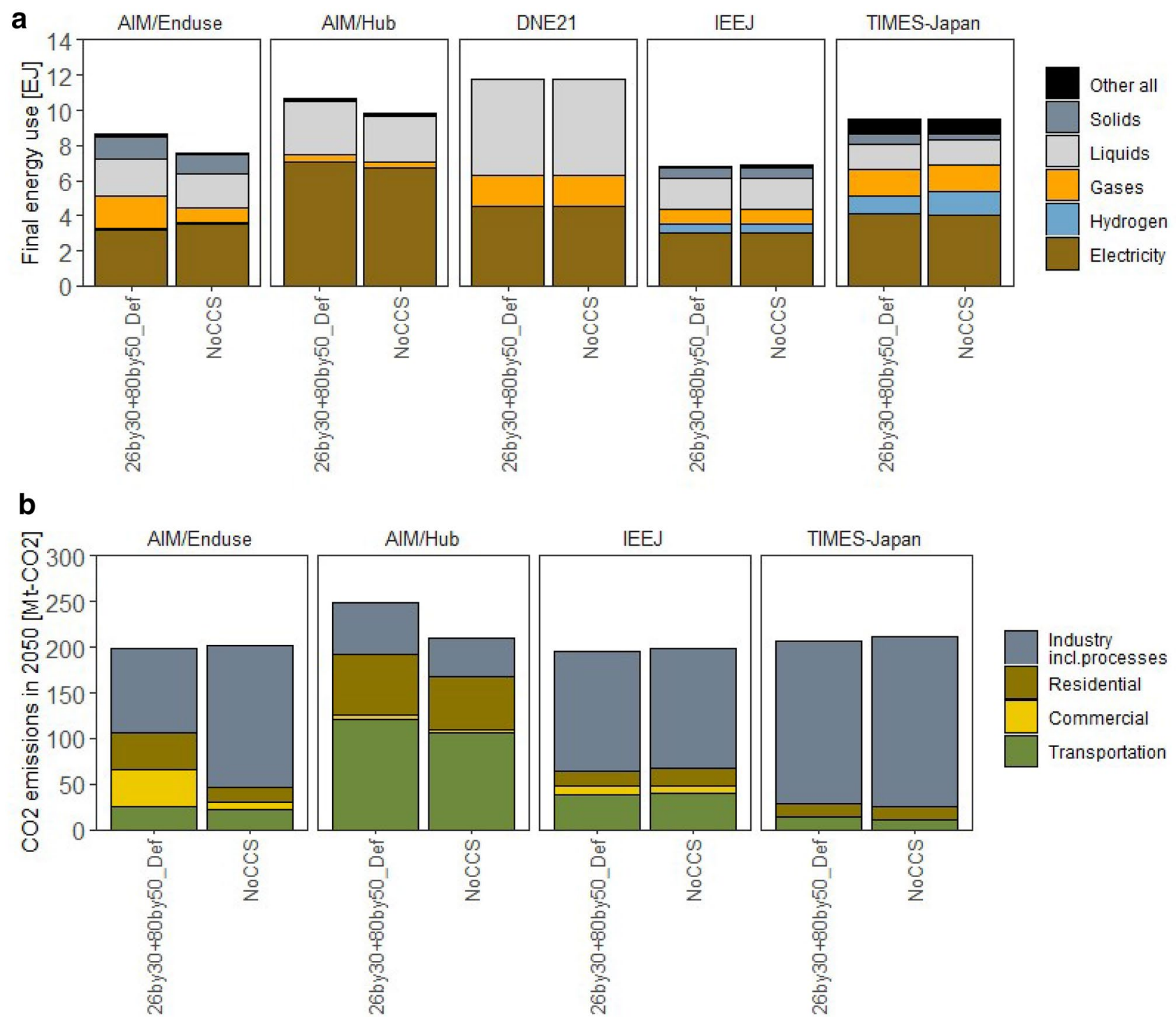

Fig. 7 Final energy use and $\mathrm{CO}_{2}$ emissions in 2050 in CCS sensitivity scenario: a Final energy use and b $\mathrm{CO}_{2}$ emissions (26by30+80by50_Def and 26by30+80by50_NoCCS). Note: DNE21 does not report $\mathrm{CO}_{2}$ emissions by sectors. DNE21 are not classified

and liquids, but in some models (DNE21, IEEJ) the gases consumption increases with tighter emissions targets. An increase in hydrogen consumption with tighter emissions targets is also observed in AIM/Enduse, IEEJ and TIMESJapan, all the models with a hydrogen option.

In AIM/Enduse, electricity consumption increases from 3.1 to $3.7 \mathrm{EJ}$ (860-1030TWh) as the emissions target gets tighter from 70 to $90 \%$. The biggest reduction seen is in gases as the consumption decreases from 2.0 to $0.9 \mathrm{EJ}$ followed by liquids from 2.3 to $1.9 \mathrm{EJ}$.

AIM/Hub's electricity consumption increases from 6.5 to 7.8EJ (1800-2160TWh) as the emissions target gets tighter from 70 to $100 \%$. The increase in the electricity consumption replaces gases and liquids as the gases decrease from 0.8 to $0.1 \mathrm{EJ}$, and liquids decrease from 4.4 to $1.0 \mathrm{EJ}$.
In DNE21, the electricity consumption stays the same from 70 to $90 \%$ reduction targets at 4.5EJ (1260TWh) but increases to 4.7EJ (1300TWh) in $100 \%$ reduction target. The consumption of liquid decreases from 6.6 to $2.3 \mathrm{EJ}$ as the emission target gets tighter from 70 to $100 \%$ as in all models, but the consumption of gases increases from 1.8 to2.7EJ.

In IEEJ, the electricity consumption increases from 2.9 to $3.0 \mathrm{EJ}$ ( $820-830 \mathrm{TWh}$ ) as the emissions target gets tighter from 70 to $80 \%$. The coal and liquids demand decrease as in other models, but the biggest increase is seen in hydrogen which increases from close to zero to $0.5 \mathrm{EJ}$. 


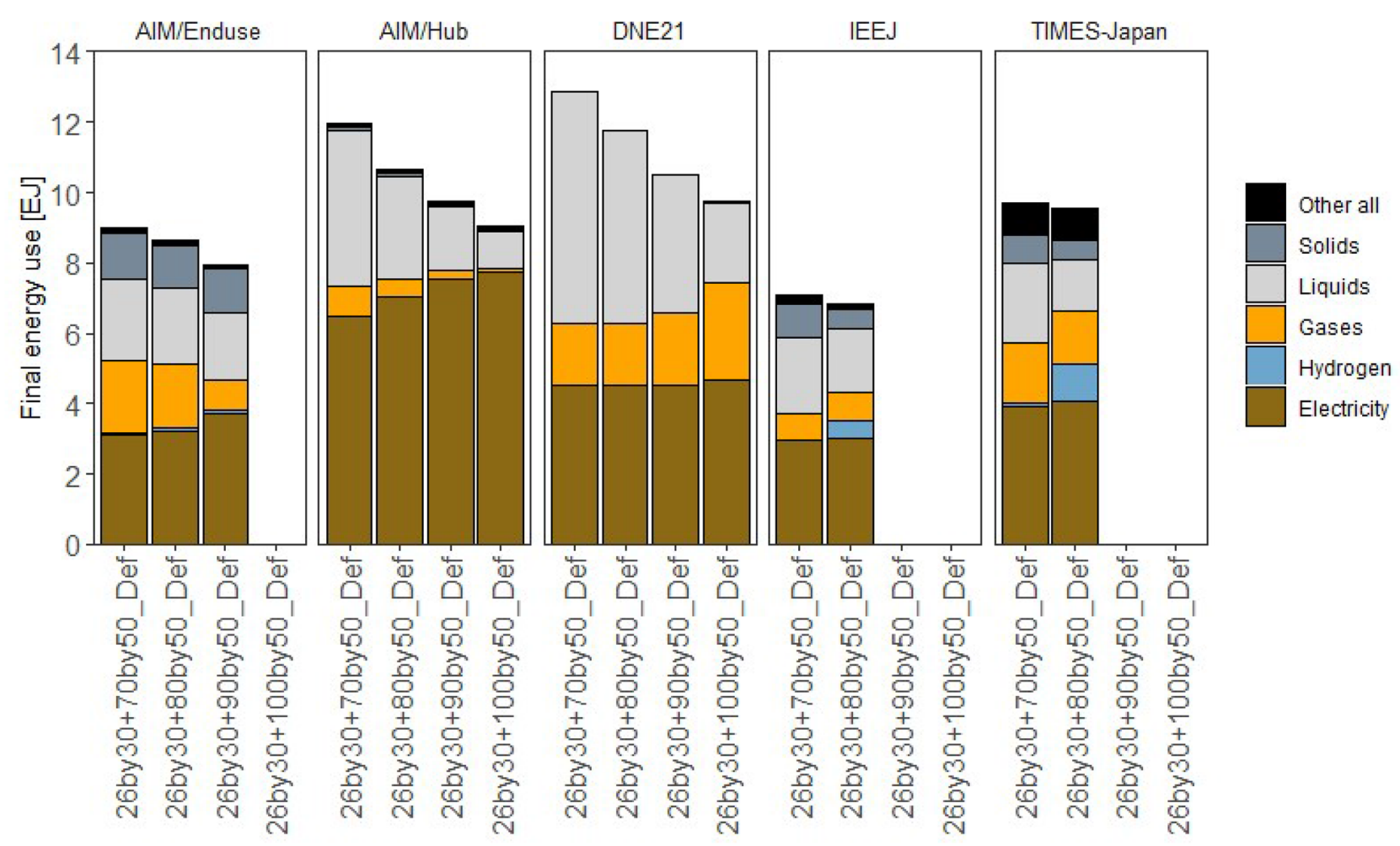

Fig. 8 Final energy use by fuel type in 2050 in emissions policy scenarios

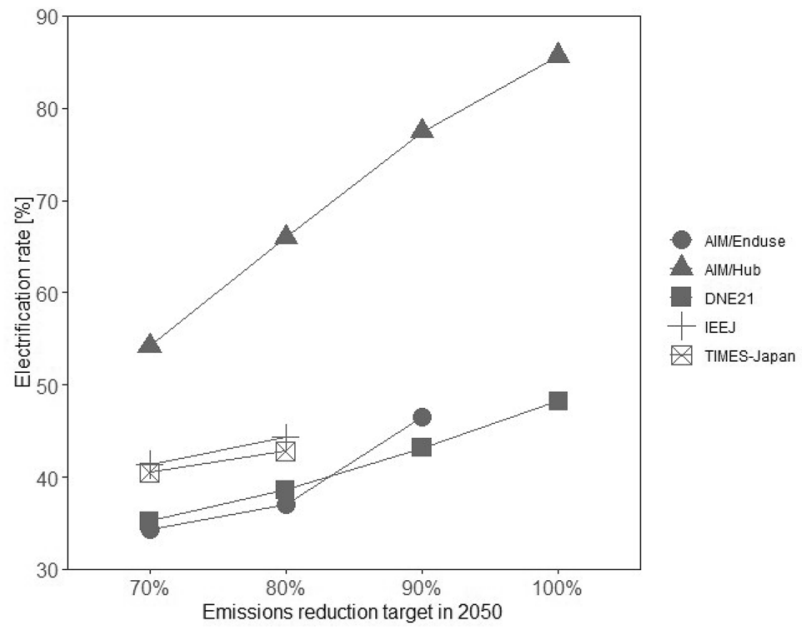

Fig. 9 Electrification rate and emissions reduction targets in 2050

In TIMES-Japan, the electricity consumption increases from 3.9 to $4.1 \mathrm{EJ}(1090-1130 \mathrm{Wh})$ as the emissions target gets tighter from 70 to $80 \%$. Like IEEJ, the TIMESJapan sees a decrease in liquids and gases while hydrogen increases the most from 0.3 to $1.2 \mathrm{EJ}$.

\section{Discussion}

\section{Electrification pace and METI outlook}

The METI outlook assumes the final energy use in 2030 to be reduced by $14 \%(14.4-12.4 \mathrm{EJ})$ while the electricity consumption to be reduced by only $5 \%(3.7-3.5 \mathrm{EJ})$ compared to 2010. Since the final energy reduction rate is higher, the METI outlook recommends electrification rate to be increased from 26 to $29 \%$ or the electrification rate to increase at the pace of $0.15 \% / y e a r$.

The electricity rate in Japan has increased from $13 \%$ in 1970 to $28 \%$ in 2018. Looking at a 20-years span, the annual percent change in electrification has been $0.37 \% / y e a r$ from 1970 to 1990 , and $0.30 \%$ /year from 1990 to 2010. Since 2011 the pace of electrification has slowed down to $0.18 \%$ / year from 2010 to 2018 .

In the 26by $30+80$ by50_Def scenario, the electrification rates increase at a pace of $0.03-0.45 \%$ /year from 2010 to 2030, showing that the historical rates and the rate assumed by METI outlook could be enough to reach the 2030 target (Fig. 10). However, as mentioned in the results section, the electrification pace must be accelerated from 2030 to 2050 and need to reach the range of $0.46-1.58 \% / y e a r$. This pace is $1.5-5.3$ times higher than the historical average of $0.30 \% /$ year (199-2010), a period of relatively electrification leading 
a

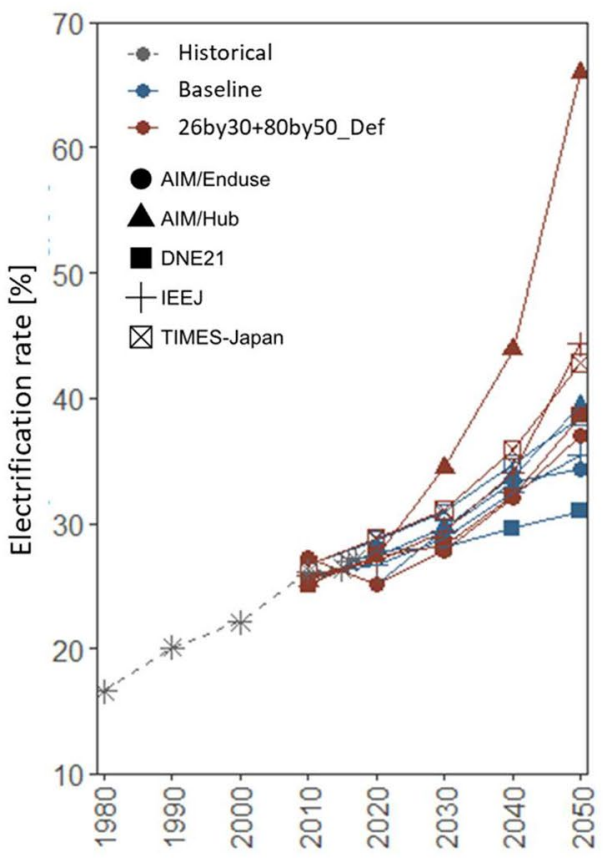

b

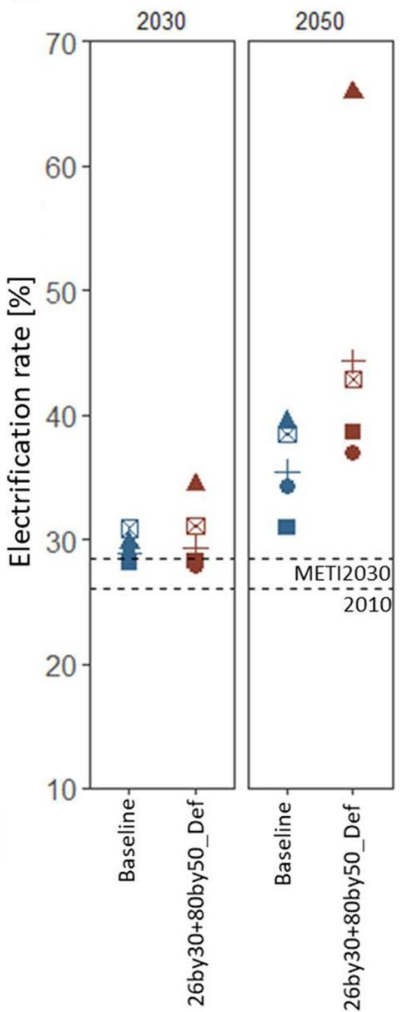

C

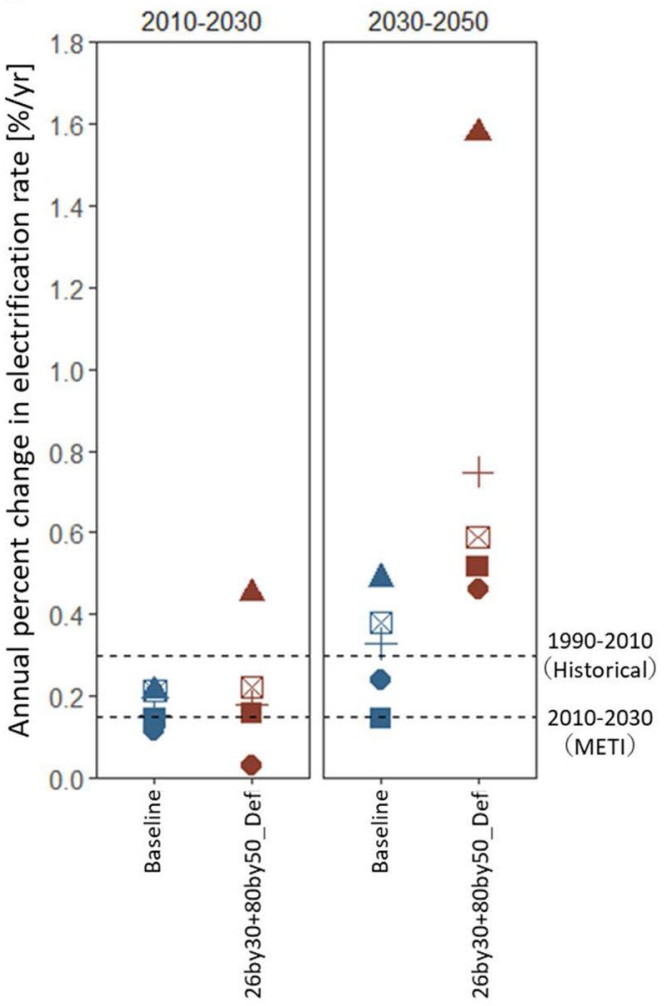

Fig. 10 Electrification rate from 1980 to 2050 in Historical, Baseline and 26by30+80by50_Def: a Electrification rate from 1980 to 2050 , b Electrification rate in 2030 and 2050, and c Average of annual change in electrification rate from 2010 to 2030 and 2030 to 2050

up to the 2011 Tohoku earthquake and tsunami. Taking into consideration that the pace of electrification in the baseline scenario, a scenario without a climate policy, is $0.14-0.49 \% /$ year from 2030 to 2050 in the 26 by $30+80$ by50_Def in 2050 , increasing electrification rates to achieve $80 \%$ reduction in 2050 will require additional policy measures. Multiple studies (Seto et al. 2016; Unruh 2000) have pointed out that a lock-in mechanism could delay the diffusion of technologies. Policies and measures to alleviating the lock-in mechanism which can delay electrification need be considered to increase the pace of electrification suggested by the models to achieve the emissions reduction target. Policymakers could refer to some advanced electrification measures recently taken to decarbonize buildings by several US states. The measures include obligation or recommendation to electrify new buildings, installation assistance for electrical equipment, the requirement for electrification ready, and providing consumers with information on benefits such as comfort and controllability of electrical equipment (Nishio and Nakano 2020).

Looking further into the sectoral electrification rates, there is no consensus among the models on the pace of electrification. Only in the transportation sector alone, which currently has a very low electrification rate, all models show that the electrification pace needs to be increased. While there are variations in the electrification rates and electricity demand by sectors among models, a common trend in enduse technology was observed in the residential, commercial and transportation sectors. The use of oil water heater and stoves decreases in the residential sector and gas appliances decreases in the commercial sector. In the transportation sector, fossil fuel vehicles decreased significantly, while they were replaced by electric and fuel cell vehicles. There is a big difference among models in terms of the timing and pace of electrification by sectors, but there is a clear conclusion that the overall electrification rate of the demand sector needs to be increased. A detailed analysis of the differences between the models of electrification pace by sector is a topic for the future. Since Ju et al. (2021) reports results of energy use in the industry sector in details from the same Model Intercomparison project.

It is also important to note that reducing emission intensity of electricity is a prerequisite for mitigation through electrification (Zhang and Fujimori 2020). In the 26 by $30+80$ by50_Def scenario, the model results show the emission intensity of electricity sharply decreases from 2040 to 2050, but a lock-in mechanism also applies to the supply sector. Along with accelerating the pace of electrification, 
the emission intensity of electricity should be reduced accordingly from an early stage.

\section{Electricity and hydrogen}

The two clean energy carriers introduced with a notable share in 2050 in this modeling comparison exercise are electricity and hydrogen. In two models in which hydrogen is not modeled, AIM/Hub and DNE21, electricity is chosen as the clean energy carrier. In other three models (AIM/Enduse, IEEJ and TIMES-Japan), hydrogen is introduced along with electricity to decarbonize the demand sectors. Hydrogen is mainly introduced in the industry and transportation sectors, as hydrogen is a good option for hard to electrify demands such as high temperature industrial heat demands, heavy trucks and ships. The residential and commercial sectors also have limited end-use technologies options available for hydrogen.

If we turn to the supply side, typically hydrogen is produced by electrolysis of water using carbon free electricity (International Energy Agency 2019), so the domestic hydrogen production is directly related to an increase in the supply-side electricity generation, not electricity demand in the demand sectors (see Figure ESM 4). In TIMESJapan, the electricity generation jumps to nearly 2000TWh in the HiVREpot scenario compared to 1350TWh in the 26 by $30+80$ by $50 \_D e f$ scenario (Note that electricity consumption in Fig. 6 does not include the electricity consumption for hydrogen production, which is categorized as secondary energy use), as hydrogen is produced domestically using more readily available wind and solar. Such an increase in the amount of power generated for hydrogen production is regarded as indirect electrification. For example, net zero emissions scenario of the UK Committee on Climate Change (2019) and Capros et al. (2019) explicitly takes into account that the amount of electricity required for electrolysis of water will occur at a level comparable to the electricity demand of the traditional demand sector. It is also possible to import hydrogen; in which case the domestic electricity generation is not affected. Such a case is IEEJ, in which all of hydrogen consumed in the model is imported.

Although METI outlook only explicitly considers electricity for the demand sector in 2030, hydrogen along with electricity could play a vital role in the future energy mix. By 2050, innovation could open the possibility of affordable domestic hydrogen production options. Therefore, the amount of electricity generation possibly required to produce hydrogen should be carefully considered in the discussion for the energy mix of 2050, for example, in the revision of the basic energy plan.

We did not discuss the role of biomass, which is one of the low-carbon carriers, in this study. Since biomass could play an important role in extreme reduction scenarios, such as zero emissions in 2050, it is necessary to consider the role of biomass together with hydrogen in the future analysis of electrification.

\section{Conclusion}

In this study, we analyzed the change in energy use structure of the demand sector in scenarios achieving $80 \%$ reduction in 2050, Japan's long-term reduction target, focusing on the role of electricity.

In order to achieve the long-term reduction target, it is necessary to significantly reduce $\mathrm{CO}_{2}$ emissions not only in the supply side but also in the demand side. The model results of the scenario that is consistent with the NDC and mid-century strategy show approximately $70 \%$ reductions in the demand-side emissions in this modeling comparison. The reduction is contributed to a significant reduction in the final energy use, especially fossil fuels, while maintaining or increasing consumption of low emission intensity electricity. The electrification rate increases mainly due to switching from fossil fuel end-use technologies (i.e. oil water heater, oil stove and combustion-engine vehicles) to electricity enduse technologies (i.e. heat pump water heater and electric vehicles).

The pace at which electrification rate must be increased is a challenge. Electrification has been advancing as a trend, but neither the past electrification pace nor the outlook of the Ministry of Economy, Trade and Industry is enough to reach the suggested electrification rate of 37-66\% suggested by the models in 2050 . Therefore, a more focus should be given on demand side electrification in the long-term strategy, and more concrete measures, such as banning the sale of combustion-engine vehicles by UK or requiring building electrification as in Berkeley, to accelerate dissemination of electricity end-use technologies across all sectors need to be established.

Supplementary Information The online version contains supplementary material available at https://doi.org/10.1007/s11625-021-00935-w.

Acknowledgements This research was supported by the Environment Research and Technology Development Fund 2-1704 of the Environmental Restoration and Conservation Agency. KO was supported by JSPS KAKENHI Grant Number JP20K14860 and the Environmental Research and Technology Development Fund (JPMEERF20201002) of the Environmental Restoration and Conservation Agency of Japan. SF and KO were supported by Sumitomo Foundation. SS was supported by the Integrated Research Program for Advancing Climate Models (TOUGOU) Grant Number JPMXD0717935457 from the Ministry of Education, Culture, Sports, Science and Technology (MEXT), Japan. RK was supported by JSPS KAKENHI Grant Number JP20H02679 and JP17H03531. DSH was supported by the Environmental Research and Technology Development Fund (JPMEERF20201002) of the Environmental Restoration and Conservation Agency of Japan and by the Strategic Operation Fund and the Strategic Research Fund of IGES. 
Open Access This article is licensed under a Creative Commons Attribution 4.0 International License, which permits use, sharing, adaptation, distribution and reproduction in any medium or format, as long as you give appropriate credit to the original author(s) and the source, provide a link to the Creative Commons licence, and indicate if changes were made. The images or other third party material in this article are included in the article's Creative Commons licence, unless indicated otherwise in a credit line to the material. If material is not included in the article's Creative Commons licence and your intended use is not permitted by statutory regulation or exceeds the permitted use, you will need to obtain permission directly from the copyright holder. To view a copy of this licence, visit http://creativecommons.org/licenses/by/4.0/.

\section{References}

Capros P, Zazias G, Evangelopoulou S, Kannavou M, Fotiou T, Siskos P, Vita A, Sakellaris K (2019) Energy-system modelling of the EU strategy towards climate-neutrality. Energy Policy 134:110960. https://doi.org/10.1016/j.enpol.2019.110960

Committee on Climate Change (2019) Net Zero - Technical Report. https://www.theccc.org.uk/publication/net-zero-technical-repor t/

Deason J, Borgeson M (2019) Electrification of buildings: potential, challenges, and outlook. Curr Sustain Renew Energy Rep 6:131-139. https://doi.org/10.1007/s40518-019-00143-2

Deep Decarbonization Pathways Project (2015) Pathways to deep Decarbonization 2015 synthesis report. https://www.iddri.org/ en/publications-and-events/report/pathways-deep-decarboniz ation-2015-synthesis-report

Duscha V, Denishchenkova A, Jakob Wachsmuth J (2019) Achievability of the Paris agreement targets in the EU: demand-side reduction potentials in a carbon budget perspective. Clim Policy 19(2):161-174. https://doi.org/10.1080/14693062.2018.14713 85

Fortes P, Simoes S, Gouveia J, Seixas J (2019) Electricity, the silver bullet for the deep decarbonisation of the energy system? Costeffectiveness analysis for Portugal. Appl Energy 237:292-303. https://doi.org/10.1016/j.apenergy.2018.12.067

Fujii Y, Komiyama R (2015) Long-term energy and environmental strategies. In: Ahn J, Carson C, Jensen M, Juraku K, Nagasaki S, Tanaka S (eds) Reflections on the Fukushima Daiichi nuclear accident. Springer, pp 105-115

Fujimori S, Kainuma M, Masui T, Hasegawa T, Dai H (2014) The effectiveness of energy service demand reduction: a scenario analysis of global climate change mitigation. Energy Policy 75:379-391. https://doi.org/10.1016/j.enpol.2014.09.015

Fujimori S, Hasegawa S, Masui T (2017a) AIM/CGE V2.0: basic feature of the model. In: Fujimori S, Kainuma M, Masui T (eds) Post-2020 climate action global and Asian perspective. Springer, pp 305-328

Fujimori S, Hasegawa T, Masui T, Takahashi K, Silva Herran D, Dai H, Hijioka Y, Kainuma M (2017b) SSP3: AIM implementation of shared socioeconomic pathways. Glob Environ Chang 42:268-283. https://doi.org/10.1016/j.gloenvcha.2016.06.009

Fujimori S, Masui T, Matsuoka Y (2017c) AIM/CGE V2.0 model formula. In: Fujimori S, Kainuma M, Masui T (eds) Post-2020 climate action: global and Asian perspective. Springer, pp 201-303

Fujimori S, Oshiro K, Shiraki H, Hasegawa T (2019) Energy transformation cost for the Japanese mid-century strategy. Nat Commun 10(1):4737. https://doi.org/10.1038/s41467-019-12730-4

Gambhir A et al (2019) Energy system changes in $1.5^{\circ} \mathrm{C}$, well below $2{ }^{\circ} \mathrm{C}$ and $2{ }^{\circ} \mathrm{C}$ scenarios. Energy Strategy Rev 23:69-80. https ://doi.org/10.1016/j.esr.2018.12.006
Government of Japan (2019) The long-term strategy under the paris agreement. https://unfccc.int/sites/default/files/resource/ The $\% 20$ Long-term $\% 20$ Strategy $\% 20$ under $\% 20$ the $\% 20$ Paris $\% 20$ Agreement.pdf

Government of UK (2017) UK plan for tackling roadside nitrogen dioxide concentrations. https://assets.publishing.service.gov. uk/government/uploads/system/uploads/attachment_data/ file/633270/air-quality-plan-detail.pdf

Hill G, Heidrich O, Creutzig F, Blythe P (2019) The role of electric vehicles in near-term mitigation pathways and achieving the UK's carbon budget. Appl Energy 251:113111. https://doi. org/10.1016/j.apenergy.2019.04.107

Hosoya Y, Fujii Y (2011) Analysis of energy strategies to halve $\mathrm{CO}_{2}$ emissions by the year 2050 with a regionally disaggregated world energy model. Energy Procedia 4:5853-5860

Intergovernmental Panel on Climate Change (2014) Climate Change 2014: Mitigation of Climate Change. Contribution of Working Group III to the Fifth Assessment Report of the Intergovernmental Panel on Climate Change, Cambridge University Press

Intergovernmental Panel on Climate Change (2018) Global Warming of $1.5^{\circ} \mathrm{C}$ : An IPCC Special Report on the impacts of global warming of $1.5^{\circ} \mathrm{C}$ above pre-industrial levels and related global greenhouse gas emissions pathways, in the context of strengthening the global response to the threat of climate change, sustainable development, and efforts to eradicate poverty

International Energy Agency (2019) The future of hydrogen. Seizing today's opportunities. https://www.iea.org/reports/the-futur e-of-hydrogen

Ju Y, Sugiyama M, Kato E et al (2021) Industrial decarbonization under Japan's national mitigation scenarios: a multi-model analysis. Sustain Sci. https://doi.org/10.1007/s11625-021-00905-2

Kainuma M, Matsuoka Y, Morita T (2003) Climate policy assessment: Asia-Pacific integrated modeling. Springer, Tokyo

Kato E, Kurosawa A (2019) Evaluation of Japanese energy system toward 2050 with TIMES-Japan-deep decarbonization pathways. Energy Procedia 158:4141-4146. https://doi. org/10.1016/j.egypro.2019.01.818

Kurosawa A, Hagiwara N (2012) Long term energy system analysis of Japan after March 11, 2011, 3rd IAEE Asian Conference, February 21. https://eneken.ieej.or.jp/3rd_IAEE_Asia/pdf/paper /106p.pdf. [accessed 29 May 2020]

Loulou R, Remne U, Kanudia A, Lehtila A, Goldstein G (2005) Documentation for the TIMES model-part I. http://iea-etsap .org/docs/TIMESDoc-Intro.pdf. [accessed 29 Apr 2020]

Luderer G, Vrontisi Z, Bertram C, Edelenbosch OY, Pietzcker RC, Rogelj J, De Boer HS, Drouet L, Emmerling J, Fricko O, Fujimori S, Havlík P, Iyer G, Keramidas K, Kitous A, Pehl M, Krey V, Riahi K, Saveyn B et al (2018) Residual fossil $\mathrm{CO}_{2}$ emissions in $15-2{ }^{\circ} \mathrm{C}$ pathways. Nat Clim Change 8(7):626-633. https:// doi.org/10.1038/s41558-018-0198-6

Luh S, Budinis S, Giarola S, Schmidt T, Hawkes A (2020) Longterm development of the industrial sector-Case study about electrification, fuel switching, and CCS in the USA. Comput Chem Eng 133:106602. https://doi.org/10.1016/j.compchemen g.2019.106602

Matsuo Y, Endo S, Nagatomi Y, Shibata Y, Komiyama R, Fujii Y (2020) Investigating the economics of the power sector under high penetration of variable renewable energies. Appl Energy 267:113956. https://doi.org/10.1016/j.apenergy.2019.113956

Matsuo Y, Yanagisawa A, Yamashita Y (2013) A global energy outlook to 2035 with strategic considerations for Asia and Middle East energy supply and demand interdependencies. Energy Strategy Rev 2:79-91. https://doi.org/10.1016/j.esr.2013.04.002

Matsuo Y et al (2018) A quantitative analysis of Japan's optimal power generation mix in 2050 and the role of $\mathrm{CO}_{2}$-free 
hydrogen. Energy 165:1200-1219. https://doi.org/10.1016/j. energy.2018.09.187

Ministry of the Environment (2016) Long-term, low-carbon vision. https://www.env.go.jp/council/06earth/y0618-14/mat03-1.pdf

Ministry of the Environment. https://www.env.go.jp/earth/ondanka/ ghg-mrv/emissions/results/material/kakuhou_all_2018.pdf

Nishio K, Nakano K (2020) Study on initiatives for building decarbonization-Case studies of US states and local governments and implications for Japan-, CRIEPI Research Report, Y19005. (in Japanese)

Oshiro K, Masui T (2015) Diffusion of low emission vehicles and their impact on $\mathrm{CO}_{2}$ emission reduction in Japan. Energy Policy 81:215-225. https://doi.org/10.1016/j.enpol.2014.09.010

Oshiro K et al (2017) Implications of Japan's 2030 target for long-term low emission pathways. Energy Policy 110:581-587. https://doi. org/10.1016/j.enpol.2017.09.003

Oshiro K, Gi K, Fujimori S, van Soest HL, Bertram C, Després J, Masui T, Rochedo P, Roelfsema M, Vrontisi Z (2019) Mid-century emission pathways in Japan associated with the global $2{ }^{\circ} \mathrm{C}$ goal: National and global models' assessments based on carbon budgets. Clim Change. https://doi.org/10.1007/s10584-019-02490 $-\mathrm{x}$

Oshiro K, Fujimori S (2020) Stranded investment associated with rapid energy system changes under the mid-century strategy in Japan. Sustain Sci. https://doi.org/10.1007/s11625-020-00862-2

Ozawa A et al (2018) Hydrogen in low-carbon energy systems in Japan by 2050: the uncertainties of technology development and implementation. Int J Hydrogen Energy 43:18083-18094. https://doi. org/10.1016/j.ijhydene.2018.08.098

Quiggin D, Buswell R (2016) The implications of heat electrification on national electrical supply-demand balance under published 2050 energy scenarios. Energy 98:253-270. https://doi. org/10.1016/j.energy.2015.11.060

Prime Minister's Office of Japan (2020) Prime Minister Suga's statement of belief. https://www.kantei.go.jp/jp/99_suga/state ment/2020/1026shoshinhyomei.html

Raghavan S, Wei M, Kammen D (2017) Scenarios to decarbonize residential water heating in California. Energy Policy 109:441-451. https://doi.org/10.1016/j.enpol.2017.07.002

Sato O (2005) A study on long-term energy scenarios for Japan. JAERI-Res. https://doi.org/10.11484/jaeri-research-2005-012 ((in Japanese) [accessed May 29, 2020])

Seto K et al (2016) Carbon lock-in: types, causes, and policy implications. Annu Rev Environ Resour 41:425-452. https://doi. org/10.1146/annurev-environ-110615-085934

Shiraki H, Sugiyama M, Matsuo Y et al (2021) The role of renewables in the Japanese power sector: implications from the EMF35 JMIP. Sustain Sci. https://doi.org/10.1007/s11625-021-00917-y

Silva HD, Fujimori S, Kainuma M (2019) Implications of Japan's long term climate mitigation target and the relevance of uncertain nuclear policy. Clim Policy 19(9):1117-1131. https:// doi.org/10.1080/14693062.2019.1634507

Sugiyama M (2012) Climate change mitigation and electrification. Energy Policy 44:464-468. https://doi.org/10.1016/j.enpol .2012 .01 .028

Sugiyama M, Akashi O, Wada K, Kanudia A, Li J, Weyant J (2014) Energy efficiency potentials for global climate change mitigation. Clim Change 123(3-4):397-411. https://doi.org/10.1007/s1058 4-013-0874-5

Sugiyama M, Fujimori S, Wada K, Endo S, Fujii Y, Komiyama R, Kato E, Kurosawa A, Matsuo Y, Oshiro K, Sano F, Shiraki H (2019) Japan's long-term climate mitigation policy: multi-model assessment and sectoral challenges. Energy 167:1120-1131. https://doi. org/10.1016/j.energy.2018.10.091

Sugiyama M, Fujimori S, Wada K et al (2021) EMF 35 JMIP study for Japan's long-term climate and energy policy: scenario designs and key findings. Sustain Sci. https://doi.org/10.1007/s11625-02100913-2

Unruh G (2000) Understanding carbon lock-in. Energy Policy 28:817830. https://doi.org/10.1016/S0301-4215(00)00070-7

Wachsmuth J, Duscha V (2019) Achievability of the Paris targets in the EU-the role of demand-side-driven mitigation in different types of scenarios. Energ Effi 12:403-421. https://doi.org/10.1007/ s12053-018-9670-4

Wakiyama T, Kuramochi T (2017) Scenario analysis of energy saving and $\mathrm{CO} 2$ emissions reduction potentials to ratchet up Japanese mitigation target in 2030 in the residential sector. Energy Policy 103:1-15. https://doi.org/10.1016/j.enpol.2016.12.059

Wei M, Nelson J, Greenblatt J, Mileva A, Johnston J, Ting M, Yang C, Jones C, McMahon J, Kammen D (2013) Deep carbon reductions in California require electrification and integration across economic sectors. Environ Res Lett 8(1):014038. https://doi. org/10.1088/1748-9326/8/1/014038

Williams J et al (2012) The technology path to deep greenhouse gas emissions cuts by 2050: pivotal role of electricity. Science 335:53-59. https://doi.org/10.1126/science.1208365

Zhang Q, Ishihara K, Mclellan B, Tezuka T (2012) Scenario analysis on future electricity supply and demand in Japan. Energy 38:376385. https://doi.org/10.1016/j.energy.2011.11.046

Zhang R, Fujimori S (2020) The role of transport electrification in global climate change mitigation scenarios. Environ Res Lett 15:034019. https://doi.org/10.1088/1748-9326/ab6658

Publisher's Note Springer Nature remains neutral with regard to jurisdictional claims in published maps and institutional affiliations. 